\title{
Defensive burying as a function of insulin-induced hypoglycemia and type of aversive stimulation
}

\author{
STEPHEN F. DAVIS and SHALA A. ROSSHEIM \\ Emporia State University, Emporia, Kansas 66801
}

\begin{abstract}
Sixty albino rats were tested for defensive-burying behavior after receiving one exposure to an aversive stimulus (electric shock or the discharge of a flashbulb). Within each of these stimulus treatments, separate groups $(\mathrm{n}=10)$ were tested under insulin-, saline-, and no-injection conditions. Two additional control groups $(n=10)$ were tested under no-flash and no-shock conditions. Subjects exposed to the flash accumulated more bedding material around the aversive stimulus than did subjects exposed to the shock. However, shock subjects spent more time engaged in burying behavior than did flash subjects. It was also shown that insulininjected subjects spent less time burying and accumulated less bedding material around the aversive stimulus than did the other subjects exposed to the aversive stimuli. No burying behavior was observed in the control animals.
\end{abstract}

In a series of recent reports, Pinel and his collaborators (e.g., Pinel \& Treit, 1978, 1979; Terlecki, Pinel, \& Treit, 1979) have shown that rat subjects, given the opportunity, may choose to bury an aversive stimulus rather than flee, freeze, or attack. Data showing that rats will bury a wide variety of aversive stimuli-an electric shock prod, a flashbulb, a mousetrap, a tube that delivered an air blast (Terlecki et al., 1979)-and employ several types of burying material-commercial bedding, sand, and cubes of wood (Pinel \& Treit, 1979)-attest to the robustness of this phenomenon.

The present defensive-burying research was prompted by a recent series of experiments investigating the relationship between hypoglycemia (low blood-sugar level) and aggression. Using the single-animal shockelicited aggression task, it has been shown (Davis, Gussetto, Tramill, Neideffer, \& Travis-Neideffer, 1978; Neideffer, Travis, Davis, Voorhees, \& Prytula, 1977) that as blood-sugar level is reduced via subcutaneous injections of insulin, aggressive responding is increased. Further, Davis, Cronin, Meriwether, Neideffer, and Travis-Neideffer (1978) have shown that this heightened state of aggression does not adapt to repeated insulin injections.

The positive relationship between hypoglycemia and aggression shown in the single-animal shock-elicited aggression task suggests that low blood-sugar level may also be influential in determining the amount of defensive burying that is observed. More specifically, based on the previous shock-elicited aggression data, one might be tempted to speculate that the defensive-burying response

This research was supported, in part, by a grant from the Research and Creativity Committee of Emporia State University to the first author. Portions of this paper were presented at the meeting of the Southwestern Psychological Association, 1979. would be heightened by the creation of the hypoglycemia state.

\section{METHOD}

Subjects

Eighty male albino rats purchased from the Holtzman Company, Madison, Wisconsin, served as subjects. All animals were approximately 120 days old at the beginning of the experiment. The subjects were individually caged in the general animal colony, with water and food available on a free-feeding basis.

\section{Apparatus}

The subjects were tested in a rectangular Plexiglas and glass enclosure $(25 \mathrm{~cm}$ wide, $45 \mathrm{~cm}$ long, $30 \mathrm{~cm}$ high). The floor of the testing chamber consisted of $4.00 \mathrm{~cm}$ of San-I-Cel animal bedding material (Paxton Processing Company, Paxton, Illinois).

Aversive stimulation consisted of the discharge of an M-3 flashbulb or the presentation of a $5.0-\mathrm{mA}$ shock for $50 \mathrm{msec}$. A Stoelting (Model 521C) shock source was employed to deliver the shock stimulus. In all cases the device used to present the aversive stimulus was mounted in the center of an end (Plexiglas) wall of the testing chamber, $1 \mathrm{~cm}$ above the beddingmaterial floor. An opaque plastic cylinder $(3 \mathrm{~cm}$ in diameter) was in place and extended $3.5 \mathrm{~cm}$ into the testing chamber when the flashbulb stimulus was used. The flashbulb was mounted inside the cylinder, with contact leads exiting via a $2.0-\mathrm{cm}$ hole directly behind it. A $1.5-\mathrm{cm}$ dowel rod wrapped with uninsulated copper wire was used to present the electric shock stimulus. When in place, the shock prod extended $4 \mathrm{~cm}$ into the testing chamber. Shock leads also exited the testing chamber via the $2.0-\mathrm{cm}$ hole.

\section{Procedure}

As subjects were housed in standard wire-bottom cages, each subject received a 4-h habituation period to the San-I-Cel bedding material $48 \mathrm{~h}$ before defensive-burying testing. Habituation sessions were conducted in rectangular tanks similar, except for the absence of an aversive stimulus device, to that used for testing.

The procedure for conducting a defensive-burying trial consisted of placing the test subject in the center of the testing chamber facing away from the aversive stimulus. A Standard 
electric timer was manually activated when the subject's feet touched the bedding floor. As soon as the subject came in close proximity (in the case of the flashbulb) or made contact (in the case of the electric shock) with the aversive stimulus device, the stimulus was presented and the timer stopped. A second Standard Electric timer was activated simultaneously with the presentation of the aversive stimulus. This timer was stopped when the subject began to engage in defensive-burying activities. Thus, times reflecting the latency to make initial contact with the aversive stimulus and the latency of the onset of defensive burying once the aversive stimulus was presented were recorded for each subject.

All subjects were confined to the testing chamber for $15 \mathrm{~min}$ following the presentation of the aversive stimulus. Using Standard electric timers, two observers independently recorded the amount of time spent in defensive burying (the movement of bedding material toward or over the aversive stimulus) during this period. At the completion of each test session, the height of the additional bedding material accumulated around the aversive stimulus was measured at three points (left, right, and center), each located $3 \mathrm{~cm}$ from the stimulus object. As the floor of the testing chamber was smoothed to a uniform $(4-\mathrm{cm})$ height prior to the testing of each subject, it was possible to calculate the exact height of the additional bedding material that was accumulated in these locations during each test session.

Four groups of subjects were tested within each aversive stimulus condition. Two groups of burying control subjects (NF, no flash; NS, no shock) did not receive an aversive stimulus during the 15-min test session. Subjects in Groups IF (insulin flash) and IS (insulin shock) were administered a 12-unit subcutaneous injection of U-40 zinc insulin ${ }^{1}$ (regular Iletin, Eli Lilly \& Company) $1 \mathrm{~h}$ before testing. Subjects in Groups SF (saline flash) and SS (saline shock) receive a 12-unit subcutaneous injection of $.09 \%$ isotonic saline $1 \mathrm{~h}$ before testing and served as injection control subjects. Finally, subjects in Groups F (flash) and S (shock) were tested in the presence of the aversive stimulus, but they did not receive any type of injection. These groups, when compared with Groups SS and $\mathrm{SF}$, served as controls for the evaluation of any effects that might be due to the receipt of the injection prior to testing.

\section{RESULTS AND DISCUSSION}

As a high degree of agreement $(r=.93)$ existed between the two observers regarding the amount of time each subject engaged in defensive burying, the two burying times for each subject were averaged before graphing and statistical analysis. A single score representing the height of the additional bedding material accumulated around the aversive stimulus was obtained for each subject by averaging the left, right, and center measurements taken after each test session. These scores were used for graphing and analysis purposes. Group means reflecting the time spent in burying behavior and the height of the additional bedding material accumulated around the aversive stimulus are shown in Figures 1 and 2, respectively. As the subjects in Groups NF and NS failed to show burying behavior, they were excluded from statistical analyses.

Separate analyses of variance performed on the latency of contact and latency of burying onset data failed to yield significant results. Thus, the subjects exposed to an aversive stimulus, regardless of injection condition, did not differ in terms of either willingness to initially approach the aversive stimulus or the onset

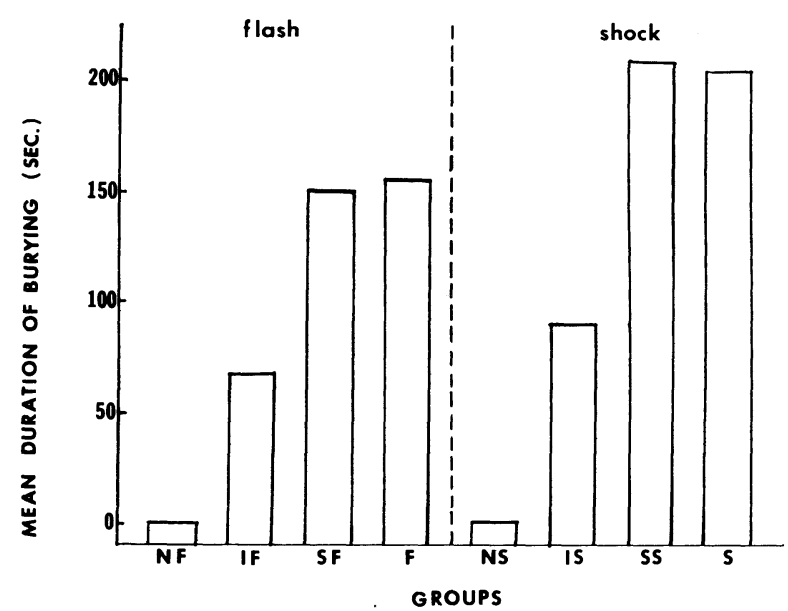

Figure 1. Mean time (in seconds) spent in burying behavior during the 15-min test session.

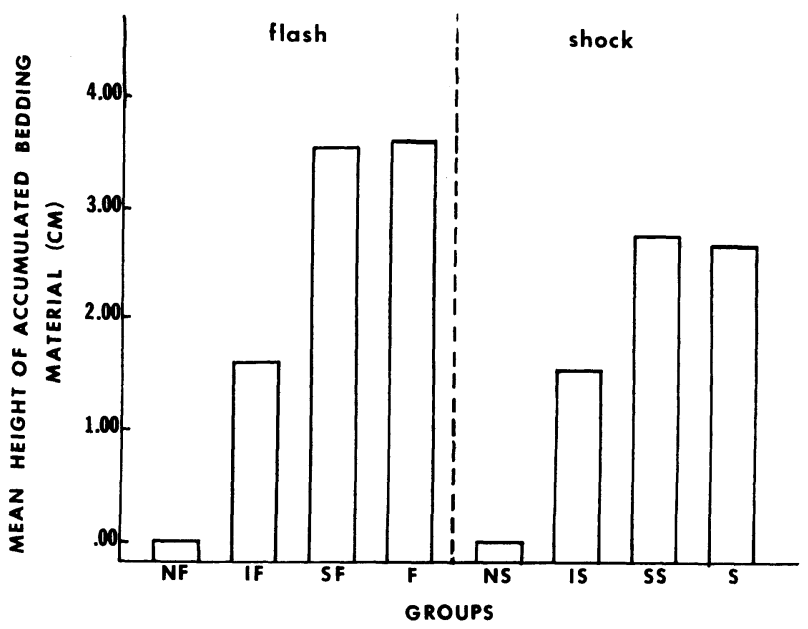

Figure 2. Mean height of burying material accumulated around the aversive stimulus during the 15-min test session.

of defensive burying once the stimulus was presented.

Analysis of variance of the time-spent-in-burying data yielded significance for the groups (no injection vs. saline vs. insulin $[\mathrm{F}(2,54)=12.94, \mathrm{p}<.01]$ and type of stimulation (flash vs. shock) $[F(1,54)=4.70, p<.05]$ factors. Thus, the statistical results are supportive of the graphical impression (Figure 1) that the subjects exposed to the shock spent more time burying than did the subjects exposed to the flash. The Newman-Keuls procedure, used to examine the specific nature of the significant groups effect, indicated that noninjection and salineinjection subjects spent significantly $(p<.01)$ more time engaged in defensive burying than did the insulininjection subjects, but they did not differ from each other.

Analysis of variance of the height of the additional accumulated burying material data also yielded significance for the groups $[F(2,54)=14.17, p<.01]$ and type of stimulation $[F(1,54)=4.49, \mathrm{p}<.05]$ factors. Also in accord with the time data, the Newman-Keuls 
analysis indicated that the no-injection and salineinjection subjects accumulated significantly $(\mathrm{p}<.01)$ more bedding material around the aversive stimulus than did the insulin-injection subjects, but they did not differ from each other. Unlike the time data, however, these results indicated that the subjects exposed to the flash stimulus accumulated significantly more bedding material around the aversive stimulus than did the shock subjects. Thus, even though the shock subjects spent more time in burying behavior, their efforts were not as uniformly directed toward covering the aversive stimulus as were those of the flash subjects.

In view of the previously mentioned hypoglycemiaaggression data, the depressed performance shown by Groups IF and IS in the present study was somewhat unexpected. However, consideration of data from a recent study (Neideffer, Davis, \& Travis-Neideffer, 1980) relating hypoglycemia and active avoidance performance may offer a possible explanation. In this study, it was shown that insulin-injected subjects displayed significantly inferior active avoidance performance when compared with injection controls. The fact that only two of the insulin subjects learned to avoid footshock, compared with $100 \%$ avoidance on the part of the control subjects, suggests that physical application(s) of the aversive stimulus may be the crucial factor. In the previously mentioned insulin and shockelicited aggression studies, a total of 200 shocks were administered to each subject. What the active avoidance (Neideffer et al., 1980) and present defensive-burying data appear to indicate is that one presentation of the aversive stimulus during a trial or test session is not sufficient to bring the level of either avoidance or burying behavior to that of comparable control subjects.

Finally, it appears important to point out that the present data are certainly supportive of the robustness of the defensive-burying phenomenon. Previously reported burying studies (Pinel \& Treit, 1978, 1979; Pinel, Treit, \& Wilkie, 1980; Terlecki et al., 1979; Wilkie, MacLennon, \& Pinel, 1979) have all employed hooded rats as subjects. Albino rats served as subjects in the present experiment. Also, differences between the conduct of such experiments by Pinel and his collaborators and the procedures used in the present experiment (e.g., habituation and testing arrangements) did not appear to influence the display of this behavior.

\section{REFERENCES}

Davis, S. F., Cronin, E. L., Meriwether, J. A., Neideffer, J., \& Travis-Neideffer, M. N. Shock-elicited attack and biting as a function of chronic vs. acute insulin injection. Bulletin of the Psychonomic Society, 1978, 12, 149-151.

Davis, S. F., Gussetto, J. K., Tramill, J. L., Neideffer, J., \& Travis-Neideffer, M. N. The effects of extended insulin dosage on target-directed attack and biting elicited by tailshock. Bulletin of the Psychonomic Society, 1978, 12, 80-82.

Neideffer, J., Davis, S. F., \& Travis-Neideffer, M. N. Active avoidance responding as a function of insulin-induced hypoglycemia. Bulletin of the Psychonomic Society, 1980, 15, 324-326.

Neideffer, J., Travis, M. N., Davis, S. F., Voorhees, J. W., \& Prytula, R. E. Sweet and sour rats: The effect of insulin dosage on shock-elicited aggression. Bulletin of the Psychonomic Society, 1977, 10, 311-312.

Pinel, J. P. J., \& Treit, D. Burying as a defensive response in rats. Journal of Comparative and Physiological Psychology, 1978, 92, 708-712.

Pinel, J. P. J., \& Treit, D. Conditioned defensive burying in rats: Availability of burying materials. Animal Learning \& Behavior, 1979, 7, 392-396.

Pinel, J. P. J., Treit, D., \& Wilkie, D. M. Stimulus control of defensive burying in the rat. Learning and Motivation, 1980, 11, 150-163.

Terlecki, L. J., Pinel, J. P. J., \& Treit, D. Conditioned and unconditioned defensive burying in the rat. Learning and Motivation, 1979, 10, 337-350.

Wilkie, D. M., Maclennon, A. J., \& Pinel, J. P. J. Rat defensive behavior: Burying noxious food. Journal of the Experimental Analysis of Behavior, 1979, 31, 299-306.

\section{NOTE}

1. The 12-unit dose was employed because it had been shown by previous research to produce the maximum amount of shock-elicited aggression in comparable animals. Analysis of blood-glucose levels from a sample of similar, nonfasted subjects $(n=10)$ indicated that the mean glucose level was $33.66 \mathrm{mg} /$ $100 \mathrm{ml}$ blood $(\mathrm{SD}=1.78)$.

(Received for publication July 17, 1980.) 